\title{
Diferentes níveis de energia metabolizável para galos reprodutores de corte com ou sem retirada da crista
}

\author{
Different levels of metabolizable energy for broiler breeders of cutting with or without \\ the crest cutting
}

\author{
Walter Lucca ${ }^{\mathrm{I}}$ Alexandre Pires Rosa ${ }^{\mathrm{II}}$ Rodrigo Uttpatel ${ }^{\mathrm{I}}$ Harvey Machado ${ }^{\mathrm{II}}$ \\ Camila Borba Santos ${ }^{\mathrm{I}}$ Vivian Barcelos ${ }^{\mathrm{IV}}$
}

\section{RESUMO}

\begin{abstract}
O experimento foi conduzido com o objetivo de avaliar qual o melhor nível energético na dieta para galos reprodutores de corte da linhagem Cobb 500 e a influência da presença da crista em parâmetros como: peso corporal, volume de sêmen, concentração de células espermáticas e fertilidade. Foram utilizados 32 galos de 22 até 44 semanas de idade, distribuídos aleatoriamente em gaiolas metálicas com comedouro e bebedouro tipo calha. Utilizou-se um delineamento experimental inteiramente casualizado, em esquema fatorial $2 \times 2$, sendo dois níveis de energia (2600 e $2800 \mathrm{kcal} \mathrm{EM} \mathrm{kg}^{-1}$ ) e duas condições de crista (com e sem corte), formando quatro tratamentos com oito repetições, com uma ave por unidade experimental. $\mathrm{Na} 24^{a}$ semana, iniciou-se a coleta de dados para a análise estatística, sempre intercalando a semana de pesagem das aves com a coleta de sêmen, o qual foi coletado através do método Americano e, para contagem de células espermáticas, fez-se a diluição do sêmen a base de formol salina tamponada para posterior leitura na câmara de Neubauer. Avaliou-se a fertilidade dos machos inseminando artificialmente seis fêmeas por tratamento, duas vezes por semana com 0,05mL de sêmen por fêmea. Os ovos foram coletados quatro vezes por dia, identificados, desinfetados $e$ incubados em condições similares. No $21^{\circ}$ dia de incubação, os ovos que não eclodiram foram quebrados e examinados macroscopicamente para calcular a fertilidade. Os níveis de energia estudados não revelaram diferença significativa no peso corporal e no volume de sêmen dos galos durante o período experimental. Já o corte da crista reduziu 9,5\% do peso corporal e $24 \%$ da fertilidade em relação a aves com

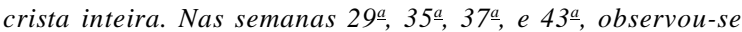
maior concentração de células espermáticas em aves que

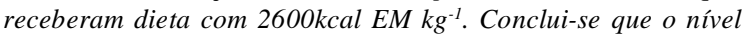

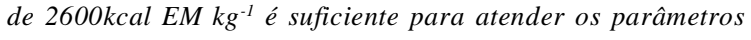
reprodutivos dos galos e a presença da crista é fundamental para manter a alta fertilidade em aves de 42 e 43 semanas de idade.

Palavras-chave: nutrição, crista, reprodutores de corte, fertilidade.

\section{ABSTRACT}

The experiment was carried out to evaluate which is the best the diet energy level diet for male broiler breeders of cutting Cobb 500 and the influence of the presence of the crest on parameters such as body weight, semen volume, sperm cell concentration and fertility. Were used 32 roosters for 22 to 44 weeks of age, they were randomly assigned to cages equipped with feeders and drinkers type gutter. The experimental design was entirely casualized in a factorial scheme $2 \times 2$ two comb conditions (with and without crest) and two levels of metabolizable energy (2600 and $\left.2800 \mathrm{kcal} \mathrm{kg}^{-1}\right)$. There was four treatments with eight replications, with one bird per experimental unit. At week $24^{\text {th }}$ began collecting data for statistical analysis, when merging the week weighing the birds to the collection of semen, which was collected through the American method and count of sperm cells, The dilution of semen-based formaldehyde buffered saline and then reading in a Neubauer chamber. We assessed male fertility through artificial insemination of six females per treatment, twice weekly with $0.05 \mathrm{~mL}$ of semen per female. Eggs were collected four times a day, identified, disinfected and incubated in the same conditions. After 21 of incubation, eggs not hatched were broken and macroscopically examined to calculate the fertility. The energy levels studied revealed no significant difference in body weight and volume of semen of roosters during the experimental

'Programa de Pós-graduação em Zootecnia, Universidade Federal de Santa Maria (UFSM), 97105-900, Santa Maria, RS, Brasil. Email: camila.borba@gmail.com. Autor para correspondência.

"Departamento de Zootecnia, UFSM, Santa Maria, RS, Brasil.

"I'Curso de Veterinária, UFSM, Santa Maria, RS, Brasil.

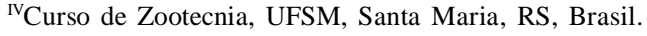


period. Since cutting the crest reduced body weight and fertility of $9.5 \%$ and $24 \%$ respectively in relation to birds crested whole. In the weeks $29^{\text {th }}, 35^{\text {th }}, 37^{\text {th }}$ and $43^{\text {th }}$ there was a higher concentration of sperm cells in birds fed the diet with $2600 \mathrm{kcal}$ $\mathrm{kg}^{-1}$. It is concluded that the level of $2600 \mathrm{kcal} \mathrm{kg}^{-1}$ is sufficient to meet the reproductive parameters of roosters and the presence of the crest is needed to maintaining high fertility in 42 and 43 weeks of age birds.

Key words: nutrition, crest, breeders of cutting, fertility.

\section{INTRODUÇÃO}

$\mathrm{O}$ intenso trabalho de pesquisadores traz o progresso em áreas como nutrição, genética, manejo, sanidade e ambiência. Este trabalho conjunto transforma a avicultura em uma atividade com excelentes resultados de produção e altamente competitiva no mercado.

O manejo nutricional da matriz de corte tem recebido maior ênfase, enquanto a nutrição do galo tem sido relegada ao segundo plano. BORGES et al. (2006) relatam que, apesar da proporção de machos representar apenas $10 \%$ em relação à das fêmeas, os machos contribuem com $50 \%$ da carga genética do plantel e são fundamentais para a fertilidade do lote.

No período reprodutivo, o desempenho das aves é influenciado pelo manejo e nutrição dos animais, por isso é importante buscar uma ação complementar entre essas áreas para se obter bons resultados. $\mathrm{Na}$ nutrição de matrizes de corte, a energia metabolizável é considerada o ponto mais crítico num sistema alimentar (LEESON \& SUMMERS, 2000), assim como o corte da crista, sendo que essa prática dificulta a dissipação do calor corporal das aves em climas quentes (KHAN \& JOHNSON, 1970). Já em regiões frias, essa função é positiva, pois a retirada da crista reduz a perda de energia dos animais, segundo estudos de FAIRFULL et al. (1985).

O consumo em excesso, o qual é predominantemente transformado em gordura, contribui para o sobrepeso corporal, redução da fertilidade, eclodibilidade e produtividade de ovos, segundo ARGENTA et al. (2001). Ou ainda o fornecimento ad libitum de alimento para reprodutores de frango de corte, estudado por ALVARENGA et al. (2006), promove uma menor produção espermática.

Existem muitas controvérsias com relação a níveis de energia metabolizável. ADJANOHOUN (1993) comprovou que, de 2650 a $2700 \mathrm{kcal} \mathrm{EM} \mathrm{kg}^{-1}$, os machos apresentaram melhor desempenho e fertilidade. PEARSON \& HERRON (1982) demonstraram que a variação de $40 \%$ no conteúdo energético da ração interfere nos parâmetros de produção, já uma variação no consumo diário de proteína de $16,5 \mathrm{~g}$ até $27 \mathrm{~g}$ não compromete esses parâmetros.

Devido ao exposto, o objetivo desta pesquisa foi avaliar qual o melhor nível energético e o efeito da retirada ou não da crista sobre o peso corporal e parâmetros reprodutivos de galos reprodutores de corte.

\section{MATERIAL E MÉTODOS}

Para a execução do estudo, foram utilizados 32 reprodutores de corte machos da linhagem Cobb 500 de 24 a 44 semanas de idade, sendo $50 \%$ das aves com crista inteira e $50 \%$ sem crista. A cauterização da crista e a vacinação contra Marek foram realizadas no $1^{\circ}$ dia de idade no incubatório da AgrogenDesenvolvimento Genético Ltda, sediada no município de Montenegro, RS.

Utilizou-se um delineamento experimental inteiramente casualizado em esquema fatorial $2 \times 2$, com duas condições de crista (cortada ou inteira) e dois níveis de energia metabolizável na dieta (2600 e 2800kcal $\mathrm{EM} \mathrm{kg} \mathrm{kg}^{-1}$ ), sendo cada tratamento constituído de oito repetições, com um galo por unidade experimental. Foram aplicados quatro tratamentos: machos com crista e $2600 \mathrm{kcal} \mathrm{EM} \mathrm{kg}^{-1}$; machos sem crista e $2600 \mathrm{kcal} \mathrm{EM}$ $\mathrm{kg}^{-1}$; machos com crista e $2800 \mathrm{kcal} \mathrm{EM} \mathrm{kg}^{-1}$; machos sem crista e $2800 \mathrm{kcal} \mathrm{EM} \mathrm{kg}^{-1}$.

As dietas utilizadas foram isoprotéicas, isocálcicas, isofosfóricas e isoaminoacíticas, formuladas de acordo com ROSTAGNO et al. (2000), somente diferindo nos níveis de energia (Tabela 1). Após a elaboração das dietas, foram coletadas amostras delas e encaminhadas para análise laboratorial na empresa CBO Assessoria \& Análise, a qual confirmou os níveis calculados.

$\mathrm{Na}$ fase de cria e de recria ( $1^{\mathrm{a}}$ a $22^{\mathrm{a}}$ semana de idade), todas as aves receberam as mesmas condições de manejo e mesmos níveis nutricionais em suas dietas. $\mathrm{Na} 20^{\mathrm{a}}$ semana de idade, os machos foram condicionados à coleta de sêmen, o que facilitou o manejo no período experimental. Após esse período, eles foram pesados e distribuídos em gaiolas individuais metálicas de $0,3 \mathrm{mx} 0,4 \mathrm{mx} 0,4 \mathrm{~m}$, com comedouro e bebedouro. A alimentação foi fornecida diariamente pela manhã sempre no mesmo horário $(8 \mathrm{~h})$ e a mesma quantidade $\left(125 \mathrm{~g}\right.$ ave $^{-1}$ dia $\left.^{-1}\right)$, variando a ração por tratamento, até o fim do experimento.

$\mathrm{Na} 24^{\text {a }}$ semana, para iniciar a coleta de dados, foi realizada a primeira pesagem corporal dos galos, repetindo-se a cada 14 dias. A coleta do sêmen foi realizada nas semanas em que não houve pesagem corporal, através do método Americano, em que o reprodutor é estimulado através de massagem 
Tabela 1 - Composição percentual e nutricional das dietas conforme os níveis energéticos (2600 e $\left.2800 \mathrm{kcal} \mathrm{kg}^{-1}\right)$.

\begin{tabular}{|c|c|c|}
\hline \multicolumn{3}{|c|}{ Níveis Energéticos ( $\mathrm{kcal} \mathrm{EM} \mathrm{kg}^{-1}$ ) } \\
\hline Ingredientes & 2800 & 2600 \\
\hline Milho & 73,08 & 61,86 \\
\hline Farelo de soja & 10,30 & 7,88 \\
\hline Farelo de trigo & 4,93 & 17,28 \\
\hline Areia & 7,66 & 8,96 \\
\hline Fosfato bicálcico & 1,82 & 1,72 \\
\hline Calcário & 1,08 & 1,12 \\
\hline Premix vit e mineral $^{1}$ & 0,50 & 0,50 \\
\hline Sal & 0,40 & 0,40 \\
\hline DL-Metionina & 0,14 & 0,15 \\
\hline L-Lisina & 0,03 & 0,06 \\
\hline L-Treonina & 0,02 & 0,03 \\
\hline Total & 100,00 & 100,00 \\
\hline \multicolumn{3}{|l|}{ Calculada: } \\
\hline Proteína Bruta (\%) & 12,00 & 12,00 \\
\hline E. Metabolizável $\left(\mathrm{kcal} \mathrm{kg}^{-1}\right)$ & 2800,00 & 2600,00 \\
\hline Extrato Etério (\%) & 3,04 & 3,01 \\
\hline Ác. Linolêico (\%) & 1,72 & 1,65 \\
\hline Cálcio & 0,90 & 0,90 \\
\hline Fósforo disponível (\%) & 0,45 & 0,45 \\
\hline Potássio (\%) & 0,47 & 0,49 \\
\hline Cloro (\%) & 0,28 & 0,29 \\
\hline Ferro (mg/g) & 0,41 & 0,37 \\
\hline Magnésio (\%) & 0,13 & 0,16 \\
\hline Sódio (\%) & 0,26 & 0,26 \\
\hline Arginina (\%) & 0,69 & 0,70 \\
\hline Glic. + Ser. (\%) & 1,15 & 1,13 \\
\hline Histidina (\%) & 0,32 & 0,31 \\
\hline Isoleucina (\%) & 0,45 & 0,44 \\
\hline Leucina (\%) & 1,16 & 1,08 \\
\hline Lisina $(\%)$ & 0,55 & 0,55 \\
\hline Metionina (\%) & 0,35 & 0,35 \\
\hline Cistina (\%) & 0,20 & 0,16 \\
\hline Met. + Cist. (\%) & 0,57 & 0,57 \\
\hline Fenilalanina (\%) & 0,55 & 0,53 \\
\hline Triptofano (\%) & 0,13 & 0,13 \\
\hline Valina (\%) & 0,55 & 0,54 \\
\hline Treonina (\%) & 0,45 & 0,45 \\
\hline
\end{tabular}

1 - Premix vitamínico e mineral: Níveis de garantia por quilograma de premix: Vit. A 2750000UI; Vit. E 6000mg; Vit. D3 150000UI; Vit. K3 500mg; Ácido Nicotínico 8000mg; Vit. B1 550mg; Vit. B2 1875mg; Vit. B6 1000mg; Ac. Fólico 250mg; Biotina 45 mg; Colina 66000mg; Ac. Pantotênico 3750mg; Metionina 89100mg; Cobre 2400mg; Ferro 12000mg; Iodo 120mg; Manganês 14000mg; Selênio 78mg e Zinco $13000 \mathrm{mg}$.

abdominal e o sêmen coletado em tubos de ensaio de vidro, graduados em mililitros, padronizado pelo "INMETRO", conforme descrito por BRILLARD (1992).

Para medir a concentração de células espermáticas, foi realizada uma diluição de $1 / 200$ seguindo a análise da técnica para bovinos, conforme BRILLARD (1992). O diluente foi uma solução de formol salina tamponada, composta de citrato de sódio $29 \%$ e formol 37\%, (96mL de citrato; $4 \mathrm{~mL}$ de formol para $100 \mathrm{~mL}$, respectivamente). O diluído foi colocado em cinco campos de cada lado da Câmara de Neubauer. Após obtenção da média, o valor foi multiplicado pela constante de diluição (10000) e expresso em número de células espermáticas $\mathrm{mm}^{-3}$, sendo considerado um bom reprodutor o macho que produzir mais de cem milhões de células espermáticas $\mathrm{mm}^{-3}$ por coleta. 
A fertilidade foi avaliada pela inseminação artificial em 192 fêmeas Barred Plymouth Rock no período entre a 42 a a 44 a semana de idade. As inseminações foram realizadas duas vezes na semana, sempre após as $14 \mathrm{~h}$, com sêmen fresco na dose de 0,05mL, conforme ROSA et al. (1995). Os ovos oriundos das fêmeas inseminadas foram coletados quatro vezes ao dia ( $8 \mathrm{~h}, 11 \mathrm{~h}, 14 \mathrm{~h}$ e $17 \mathrm{~h})$, identificados, fumigados com permanganato de potássio e formol, armazenados e incubados semanalmente. A avaliação da fertilidade foi realizada no $21^{\circ}$ dia de incubação com a contagem de pintos nascidos e embriodiagnóstico dos ovos nãoeclodidos, correspondentes a 42aㅡ, 43ㄹ e 44a semanas de idade dos galos.

No final do experimento, os dados foram submetidos à análise de variância e quando as diferenças estatísticas foram encontradas ao nível de $5 \%$ de significância, as médias foram comparadas pelo teste Tukey com auxílio do programa de estatística SAS (1997).

\section{RESULTADOS E DISCUSSÃO}

Ao avaliar os fatores isoladamente, observase que não houve efeito significativo dos níveis energéticos estudados sobre o peso corporal dos galos (Tabela 2), porém todos os machos que consumiram dieta com maior nível de energia tiveram peso corporal numericamente superior aos galos que receberam dieta com menor nível de energia, exceto na $32^{\underline{a}}$ semana.

Também evidencia-se o efeito positivo $(\mathrm{P}<0,05)$ da presença da crista sobre o peso corporal dos machos em todo período experimental, machos com crista apresentaram pesos corporais superiores aos demais (Tabela 2).

Segundo CELEGHINI et al. (2001), isso ocorre porque galos com crista desenvolvida apresentam maiores valores de volume seminal, concentração espermática, mobilidade progressiva, vigor e menor porcentagem de defeitos espermáticos, concomitantemente com maior peso corporal do que

Tabela 2 - Médias e desvio padrão do peso corporal (g) de reprodutores de corte em relação aos níveis de energia metabolizável e ao efeito crista.

\begin{tabular}{|c|c|c|c|}
\hline \multirow{2}{*}{ Semanas de idade } & \multicolumn{3}{|c|}{ 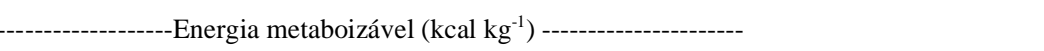 } \\
\hline & 2600 & 2800 & $\mathrm{P}$ \\
\hline 24 & $3346 \pm 351$ & $3496 \pm 423$ & 0,2170 \\
\hline 26 & $3487 \pm 362$ & $3596 \pm 409$ & 0,3658 \\
\hline 28 & $3696 \pm 324$ & $3743 \pm 431$ & 0,7031 \\
\hline 30 & $3786 \pm 396$ & $3875 \pm 405$ & 0,5079 \\
\hline 32 & $3943 \pm 368$ & $3901 \pm 513$ & 0,7152 \\
\hline 34 & $3973 \pm 366$ & $4078 \pm 628$ & 0,4719 \\
\hline 36 & $4068 \pm 383$ & $4314 \pm 618$ & 0,1306 \\
\hline 38 & $3936 \pm 421$ & $4241 \pm 746$ & 0,1212 \\
\hline 40 & $3856 \pm 445$ & $4314 \pm 852$ & 0,0496 \\
\hline 42 & $3915 \pm 444$ & $4276 \pm 854$ & 0,1211 \\
\hline 44 & $3925 \pm 484$ & $4246 \pm 866$ & 0,1895 \\
\hline Média & $3812 \pm 399$ & $4007 \pm 632$ & 0,3266 \\
\hline Semanas de idade & Sem corte da crista & Com corte da crista & $\mathrm{P}$ \\
\hline 24 & $3621 \pm 328$ & $3221 \pm 347$ & 0,0023 \\
\hline 26 & $3742 \pm 315$ & $3341 \pm 346$ & 0,0022 \\
\hline 28 & $3901 \pm 307$ & $3539 \pm 358$ & 0,0066 \\
\hline 30 & $3995 \pm 320$ & $3666 \pm 406$ & 0,0192 \\
\hline 32 & $4087 \pm 310$ & $3748 \pm 492$ & 0,0317 \\
\hline 34 & $4230 \pm 375$ & $3812 \pm 545$ & 0,0185 \\
\hline 36 & $4398 \pm 392$ & $3978 \pm 557$ & 0,0170 \\
\hline 38 & $4292 \pm 496$ & $3881 \pm 664$ & 0,0450 \\
\hline 40 & $4306 \pm 629$ & $3864 \pm 732$ & 0,0564 \\
\hline 42 & $4374 \pm 581$ & $3848 \pm 698$ & 0,0249 \\
\hline 44 & $4327 \pm 655$ & $3870 \pm 690$ & 0,0581 \\
\hline Média & $4115 \pm 428$ & $3706 \pm 530$ & 0,0253 \\
\hline
\end{tabular}

Ciência Rural, v.41, n.3, mar, 2011. 
galos sem o desenvolvimento da crista. Estes achados baseiam-se nos estudos de JAENISCH et al. (1992), que explicam que galos mais pesados têm maior desenvolvimento dos testículos, devido ao aumento da capacidade de produção de testosterona e de 5 adiidrotestosterona, responsável pelo desenvolvimento da crista.

Os tratamentos estudados não mostraram efeito sobre o volume de sêmen, mas apresentaram diferença significativa quanto ao número de células

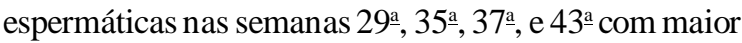
concentração de células espermáticas para dieta com 2600 $\mathrm{kcal} \mathrm{EM} \mathrm{kg}^{-1}$, conforme apresentado na tabela 3 . Esses resultados corroboram os estudos de ADJANOHOUN (1993), LESSON \& SUMMERS (2000) e ARGENTA et al. (2001), os quais relatam que a utilização de dietas com energia metabolizável de 2600 $\mathrm{kcal} \mathrm{kg}^{-1}$ proporcionam maior concentração de células espermáticas, quando comparadas às dietas com $2800 \mathrm{kcal} \mathrm{kg}^{-1}$. Porém, os resultados encontrados discordam daqueles verificados por SEXTON et al. (1989), que afirmam que quanto menor o nível de energia utilizado, menor será a concentração de células espermáticas. Quanto à interação níveis energéticos $\left(\mathrm{kcal} \mathrm{kg}^{-1}\right)$ versus efeito crista, não houve efeito significativo para a concentração de células espermáticas.

Houve redução significativa da fertilidade (Tabela 4) quando se utilizou o nível de 2800kcal EM $\mathrm{kg}^{-1} \mathrm{em}$ dietas para aves que tiveram a crista cortada. Esses resultados foram semelhantes aos encontrados por ADJANOHOUN (1993), ARGENTA et al. (2001) e LESSON \& SUMMERS (2000), que observaram que o excesso de energia consumido é transformado em gordura e consideram níveis próximos de 2600kcal EM $\mathrm{kg}^{-1}$ os ideais para peso corporal e fertilidade. No entanto, esses resultados corroboram daqueles encontrados por ATTIA et al. (1995), que não verificaram uma maior fertilidade quando na utilização de níveis mais elevados de energia, como $370 \mathrm{kcal}$ por dia.

Galos com a crista desenvolvida apresentam melhores características seminais nas primeiras semanas de reprodução do que galos com crista pouco desenvolvida. Porém, as características seminais de galos com crista pouco desenvolvida tendem a manterse melhores por mais tempo que os animais com crista, sofrendo pouca ou nenhuma influência do peso corporal, conforme estudos de CLELEGHINI et al. (2001).

\section{CONCLUSÃO}

Onível de energia metabolizável de 2600kcal $\mathrm{kg}^{-1}$ é suficiente para atender os parâmetros reprodutivos dos galos, como peso corporal, concentração de células espermáticas, volume de sêmen e fertilidade. A permanência da crista inteira para reprodutores de corte permitiu um maior peso corporal e maior fertilidade se comparado a machos com corte da crista.

\section{AGRADECIMENTOS}

Os autores agradecem ao Conselho Nacional de Pesquisa e Tecnologia (CNPq) e ao Departamento de Zootecnia, pelo apoio financeiro a este trabalho, e ao Laboratório de Avicultura (LAVIC) da Universidade Federal de Santa Maria (UFSM), pela infraestrutura e colaboração de seus estagiários.

Tabela 3 - Concentração de células espermáticas pela transformação logarítmica na base dez com relação aos níveis de energia da dieta (2600 e $2800 \mathrm{kcal} \mathrm{EM} \mathrm{kg}^{-1}$ ) (média \pm erro padrão).

\begin{tabular}{|c|c|c|c|}
\hline \multirow{2}{*}{ Semanas de idade } & \multicolumn{3}{|c|}{ Concentração de células espermáticas $\left(\mathrm{mm}^{3}\right)$ - } \\
\hline & 2600 & 2800 & $\mathrm{P}$ \\
\hline 25 & $2,06 \times 10 \pm 2,59 \times 10$ & $1,81 \times 10 \pm 1,81 \times 10$ & 0,7523 \\
\hline 27 & $1,53 \times 10 \pm 1,49 \times 10$ & $1,65 \times 10 \pm 1,37 \times 10$ & 0,8050 \\
\hline 29 & $1,52 \times 10 \pm 5,80 \times 10$ & $0,64 \times 10 \pm 1,47 \times 10$ & 0,0370 \\
\hline 31 & $1,94 \times 10 \pm 1,35 \times 10$ & $1,53 \times 10 \pm 1,55 \times 10$ & 0,4426 \\
\hline 33 & $1,92 \times 10 \pm 1,55 \times 10$ & $2,39 \times 10 \pm 1,60 \times 10$ & 0,4324 \\
\hline 35 & $2,01 \times 10 \pm 1,07 \times 10$ & $1,01 \times 10 \pm 1,03 \times 10$ & 0,0167 \\
\hline 37 & $2,35 \times 10 \pm 1,57 \times 10$ & $1,39 \times 10 \pm 1,16 \times 10$ & 0,0574 \\
\hline 39 & $2,21 \times 10 \pm 1,49 \times 10$ & $1,31 \times 10 \pm 1,26 \times 10$ & 0,0747 \\
\hline 41 & $1,36 \times 10 \pm 1,42 \times 10$ & $1,76 \times 10 \pm 1,33 \times 10$ & 0,0440 \\
\hline 43 & $1,85 \times 10 \pm 1,53 \times 10$ & $0,89 \times 10 \pm 1,08 \times 10$ & 0,0564 \\
\hline Médias & $1,87 \times 10 \pm 1,98 \times 10$ & $1,44 \times 10 \pm 1,36 \times 10$ & 0,3114 \\
\hline
\end{tabular}


Tabela 4 - Efeito dos níveis de energia metabolizável $\left(\mathrm{kcal} \mathrm{kg}^{-1}\right)$ versus efeito crista sobre a fertilidade.

\begin{tabular}{|c|c|c|c|c|c|}
\hline \multicolumn{6}{|c|}{ Fertilidade } \\
\hline Semanas de idade & $\begin{array}{c}2600 \text { crista } \\
\text { inteira }\end{array}$ & $\begin{array}{c}2600 \text { crista } \\
\text { cortada }\end{array}$ & $\begin{array}{c}2800 \text { crista } \\
\text { inteira }\end{array}$ & $\begin{array}{l}2800 \text { crista } \\
\text { cortada }\end{array}$ & $P$ \\
\hline 42 & $90,78 \mathrm{a}$ & $85,02 \mathrm{a}$ & $91,41 \mathrm{a}$ & $53,49 \mathrm{~b}$ & 0,0217 \\
\hline 43 & $93,89 \mathrm{a}$ & $88,63 a$ & $84,88 \mathrm{a}$ & $51,84 \mathrm{~b}$ & 0,0230 \\
\hline 44 & $85,09 \mathrm{a}$ & $74,15 \mathrm{a}$ & $80,70 \mathrm{a}$ & $47,13 b$ & 0,0116 \\
\hline Médias & 89,92 & 82,6 & 85,66 & 50,82 & 0,0530 \\
\hline
\end{tabular}

*Médias seguidas pelas mesmas letras minúsculas na horizontal não diferem entre si pelo teste de Tukey a 5\% de probabilidade.

\section{REFERÊNCIAS}

ADJANOHOUN, E. Manejo do macho e fertilidade. In: CONFERÊNCIA APINCO DE CIÊNCIAS E TECNOLOGIA AVÍCOLAS, 1993, Santos, SP. Anais... Santos: Fundação Apinco de Ciência e Tecnologia Avícolas, 1993. p.33-46.

ALVARENGA, A.L.N. et al. Efeito da restrição alimentar sobre o desempenho reprodutivo de galos de corte da linhagem Avian. Acta Scientiarum. Animal Sciences, v.28, n.2, p.159-163, 2006. Disponível em: <http://periodicos.uem.br/ojs/index.php/ ActaSciAnimSci/article/view/643/393>. Acesso em: 14 out. 2010. doi: $10.4025 /$ actascianimsci.v28i2.643.

ARGENTA, J.A. et al. Avaliação de programa de alimentação para matrizes de corte na fase de produção. Revista da Sociedade Brasileira de Zootecnia, v.30, n.3, p.1735-1741, 2001. Disponível em: <http://www.scielo.br/pdf/rbz/v30n6/ 7302.pdf>. Acesso em: 14 out. 2010. doi: 10.1590/S151635982001000700011 .

ATTIA,Y.A. et al. Darly energy allotments and performance of broiler breeders. 2. Females. Poultry Science, v.72 . p.247260, 1995.

BORGES, C. et al. Exigências de energia e composição da carcaça de galos reprodutores pesados em função do consumo energético na fase de reprodução. Revista Brasileira de Zootecnia, v.35, n.5, p.1978-1984, 2006. Disponível em: 〈http://www.scielo.br/pdf/rbz/v35n5/14.pdf >. Acesso em: 14 out. 2010. doi: 10.1590/S1516-35982006000700014.

BRILLARD, J.P. Production de pollitos de carne por inseminación artificial. Técnicas en Avicultura, v.8, n.43, p.1335-1339, 1992.

CELEGHINI, E.C.C. et al. Seminal characteristics evaluation of the male broiler breeder selected by comb development to reproduction. Brazilian Journal of Veterinary Research and Animal Science, v.38, n.4, p.177-183, 2001. Disponível em: < http://www.scielo.br/pdf/bjvras/v38n4/9702.pdf>. Acesso em: 14 out. 2010 . doi: 10.1590/S1413-95962001000400006.

FAIRFULL, R.W. et al. Effects of comb dubbing on the performance of laying stocks. Poultry Science, v.64, p.434439,1985 .

JAENISCH, F. R. F. et al. Correlação entre peso corporal, alterações de testículo e epidídimo e características físicas e morfológicas do sêmen de galos de linhagens pesadas. Revista Brasileira de Zootecnia, v.21, n.23, p.127-128, 1992.

KHAN, M.N.; JOHNSON, W.A. Physiological response of White leghorn layer to dubbing. Poultry Science, v.49, p.1402, 1970 .

LESSON, S.; SUMMERS, J.D.V. Broiler breeder productions. Guelph: University Books, 2000. 329p.

PEARSON, R.A.; HERRON, K.M. Effects of maternal energy and protein intakes on the incidence of malformation and malposition of the enbrio and time of death during incubation. Poultry Science, v.23, p. 71-77, 1982.

ROSA, A.P. et al. Influência de intervalos da inseminação artificial e do estresse do manejo da inseminação na produção e fertilidade de fêmeas avícolas. Ciência Rural, v.25, p.443447, 1995. Disponível em: <http://www.scielo.br/pdf/cr/v25n3/ a20v25n3.pdf> Acesso em: 14 out. 2010. doi: 10.1590/S010384781995000300020 .

ROSTAGNO, H.S. et al. Tabelas brasileiras para aves e suínos. Composição de alimentos e exigências nutricionais. Viçosa: UFV, 2000. 141p.

SAS InSTITUTE. SAS/STAT software: changes and enhancements through release 6.12. Cary, 1997.

SEXTON et al. Effects of dietary energy on semen production, fertility, plasma, testosterone and caracass composition of broiler breeder males in cages. Poultry Science, v.68, n.12, p.1688-1694, 1989. 